\title{
Effect of dried beans and silicone on intestinal hydrogen and methane production in $\operatorname{man}^{1}$
}

\author{
D. H. CALLOWAY ${ }^{2}$ AND S.E. BURROUGHS \\ From the Stanford Research Institute, Menlo Park, California, U.S.A.
}

In time, a gas which is introduced into the gut approaches equilibrium with the gas in surrounding blood and tissues. The rate at which this occurs depends upon the partial pressure of the gas and several characteristics of the membrane. The kinetics of oxygen and carbon dioxide equilibrium are additionally influenced by metabolic processes, but transfer of nitrogen and gases believed to arise exclusively within the bowel presumably depends only on diffusion (McIver, Redfield, and Benedict, 1926; Pogrund and Steggerda, 1948). Thus, hydrogen and methane are evolved in the intestine and appear as components of both breath and flatus. However, their amount and pattern of appearance after ingestion of a gas-producing meal are strikingly different. The hydrogen content of expired air rises sharply about five hours after eating a single large meal of beans and remains raised for a few hours. Peak levels of breath hydrogen coincide with subjective sensations of intestinal gas production. During this same period, methane concentration in the breath does not vary appreciably (Calloway, 1966). In a different study, it was found that the total amount of hydrogen in flatus increases when large volumes are egested in response to gas-producing food, while methane concentration may be unaffected, or it may rise or fall slightly (Kirk, 1949). These observations suggest that hydrogen and methane concentrations reflect different facets of gas evolution or transportation. To clarify and quantify these relationships, we have measured hydrogen and methane concentrations simultaneously in expired air and in rectal flatus of men fed a conventional bland diet with or without beans.

We also investigated the effect of an anti-foaming reagent, ilicoe, which reputedly relieves chronic symptoms attributed to intestinal gas and bloating Rider and Moeller, 1960). Silicone is said to alter the surface tension of small, mucus-covered gas

\footnotetext{
${ }^{1}$ Research supported by the Idaho Bean Commission.

2Present address: Department of Nutritional Sciences, University of California, Berkeley, California 94720.

${ }^{3}$ Present address: Department of Home Economics,

Polytechnic College, San Luis Obispo, California.
}

bubbles that form in the gut, causing the bubbles to coalesce, forming free gas which is easily expelled orally or rectally.

\section{MATERIALS AND METHODS}

Subjects were six male volunteers from a local Veterans Administration Hospital. They ranged in age from $\mathbf{4 0}$ to 63 years and had no illness or injury that was prejudicial to the conduct of this research. The men were available for study for four successive weeks.

Test materials were administered in random sequence at the breakfast meal on Monday, Wednesday, and Friday. Each man was fed on two occasions the reference breakfast (N) which consisted of apple sauce, white bread with margarine and jelly, soft cooked eggs, and coffee. Bean meals, given five or six times to each subject, included the same components except that canned beans replaced the eggs and part of the bread. Subjects were permitted to drink coffee during the morning and were given a bland, low-residue lunch at noon.

The two lots of canned Great Northern beans used in this study (samples $\mathrm{C}$ and $\mathrm{E}$ ) were prepared in the laboratory according to good commercial practice, except that a standard commercial brine was added rather than a seasoned sauce. There proved to be no difference in response to the two lots of beans (Fig. 1) so these are reported hereafter as the treatment group.

Silicone (methylsiloxane ${ }^{1}$ ), $30 \mathrm{mg}$ per $100 \mathrm{~g}$ dry weight of beans, was added to some of the cans before thermal processing. Silicone fluids are water repellent which made it difficult to maintain a uniform concentration throughout the beans with a liquid sauce. Therefore, subjects were required to consume on two to four test occasions the entire contents of a no. 2 can filled with $100 \mathrm{~g}$ dry beans in brine, with or without silicone. As a control measure, once in each of four subjects the influence of silicone was tested in the absence of beans, in which case methylsiloxane was added to the apple sauce.

For collection of flatus gases, a flexible rectal catheter was inserted 90 minutes after the breakfast meal and left in place until 3.30 p.m. Samples were collected hourly for six hours. Gases obtained by rectal tube were passed through anhydrite to remove water and collected in evacuated plastic bags. The dried sample was then passed through a tare-weighed U-tube filled with asbestos impregnated with sodium hydroxide (Ascarite), which 
absorbs carbon dioxide on a 1:1 basis. Flatus methane, hydrogen, and oxygen were analysed chromatographically, using nitrogen as the carrier gas. The first sample each day was discarded as it contained air from the rectal catheter and anhydrite tube. Occasionally a rectal tube was found to be plugged with faecal material, which resulted in loss of data for that day.

Samples of expired air were collected at hourly intervals, beginning two-and-a-half hours after breakfast, and analysed for hydrogen and methane content. Methods of collection and analysis have been reported elsewhere (Calloway, 1966).

\section{RESULTS}

When the conventional breakfast was taken, fivehour rectal flatus egestion was quite uniform among subjects, ranging from 206 to $344 \mathrm{ml}$ of dry gas (Table I). The group average was $241 \mathrm{ml}$; the standard deviation, $21 \mathrm{ml}$, was less than $10 \%$ of the mean. All samples contained small amounts of carbon dioxide ( 1 to $3 \%$ ), and oxygen concentration was less than $2 \%$. Flatus of subjects $D$ and $E$ contained $10 \%$ of methane; detectable but not always measurable amounts were present in all other specimens. Hydrogen was absent in four cases and a trace constituent in the others. Unidentified gases, chiefly nitrogen, accounted for 87 to $97 \%$ of the volume.

In the control condition, four of the men had low levels of methane in expired air, 4 to $8 \mathrm{ppm}$, but those whose flatus was high in methane content also had high levels in the breath, 20 to $28 \mathrm{ppm}$ (Table I). The concentration of methane did not differ appreciably from one sampling hour to another. Hydrogen production of the two highmethane subjects was low; their average five-hour value was $4 \mathrm{ppm}$ in expired air. The average concentration was 9 ppm for subject $C$ and subjects $F$ and $A$ had higher values of 14 and $18 \mathrm{ppm}$. Only subject B had no detectable hydrogen in the breath. Concentration of hydrogen was not uniform throughout the sampling period, but rather it rose sharply about one hour after the noon meal, attaining peak levels of 18 to 69 ppm (Fig. 1).

The addition of silicone alone did not alter the volume of flatus. The five-hour collection of the four men who received this treatment was $264 \pm$ $17 \mathrm{ml}$. Composition of the flatus was modified in only one case, that of subject $D$, whose methane concentration dropped from 10 to $2 \%$. The breath methane level was also reduced with silicone treatment in this subject, from 20 to $6 \mathrm{ppm}$. Neither

T A B L E I

FLATUS AND MINOR RESPIRATORY GASES OF MEN FED CONTROL AND BEAN MEALS WITH OR WITHOUT SILICONE

\begin{tabular}{|c|c|c|c|c|c|c|c|c|c|c|c|c|c|c|c|c|}
\hline \multirow{3}{*}{ Subject } & \multirow{2}{*}{\multicolumn{3}{|c|}{ Treatment }} & & & & & & & & \multicolumn{6}{|c|}{ Estimated $^{2}$ Gas Production ( $\mathrm{ml} / 5 \mathrm{hr}$ ) } \\
\hline & & & & & & & & & & & \multicolumn{3}{|c|}{ Hydrogen } & \multicolumn{3}{|c|}{ Methane } \\
\hline & Beans & $\begin{array}{l}\text { Sili- } \\
\text { cone }\end{array}$ & $N$ & \multicolumn{5}{|c|}{ Collected Flatus (per $5 \mathrm{hr}$ ) } & \multicolumn{2}{|c|}{$\begin{array}{l}\text { Concentration } \\
\text { in Breath } \\
\text { (5-hr average ppm) }\end{array}$} & Flatus & $\begin{array}{l}\text { Ex- } \\
\text { haled }\end{array}$ & Total & Flatus & $\begin{array}{l}\text { Ex- } \\
\text { haled }\end{array}$ & Total \\
\hline & & & & $\begin{array}{l}\text { Volume } \\
(m l)\end{array}$ & $\% \mathrm{CO}_{2}$ & $\% \mathrm{CH}_{4}$ & $\% \mathrm{H}_{2}$ & $\% \mathrm{O}_{2}$ & $\boldsymbol{H}_{2}$ & $\mathrm{CH}_{4}$ & & & & & & \\
\hline age 63 & - & - & 2 & 227 & $1 \cdot 4^{1}$ & $1 \cdot 0$ & 0 & 0.9 & 0 & 6 & 0 & 0 & 0 & 2 & 12 & 14 \\
\hline & + & - & 4 & $246 \pm 19^{1}$ & $8 \cdot 0 \pm 5 \cdot 7$ & $\begin{array}{l}70.3 \\
0.3\end{array}$ & $0 \cdot 1$ & 0.2 & $23 \pm 4$ & 4 & $<1$ & 46 & 46 & 1 & 8 & 9 \\
\hline & + & + & 3 & 268 & 46 & 0.3 & $0 \cdot 1$ & $1 \cdot 4$ & 19 & 6 & $<1$ & 38 & 38 & $<1$ & 12 & 12 \\
\hline age 46 & - & - & 1 & 223 & $1 \cdot 8$ & Trace & 0 & 0.7 & 9 & 8 & 0 & 18 & 18 & $<1$ & 16 & 16 \\
\hline & + & - & 6 & $234 \pm 13$ & $2 \cdot 7 \pm 0 \cdot 8$ & $2 \cdot 2 \pm 1 \cdot 0$ & 0.4 & $1 \cdot 8$ & $25 \pm 5$ & $6 \pm 0.6$ & 1 & 50 & 51 & 6 & 12 & 18 \\
\hline & + & + & 3 & 201 & $3 \cdot 6$ & 0.6 & 0 & 0.2 & 35 & 6 & 0 & 70 & 70 & 1 & 12 & 13 \\
\hline age 40 & - & - & 2 & 225 & 1.0 & 10.4 & 0 & $1 \cdot 8$ & 4 & 20 & 0 & 8 & 8 & 23 & 40 & 63 \\
\hline & + & - & 4 & $477 \pm 48$ & $10 \cdot 1 \pm 3 \cdot 5$ & $518 \cdot 0 \pm 3 \cdot 2$ & $2 \cdot 4 \pm 1 \cdot 1$ & $2 \cdot 8$ & $24 \pm 3$ & $21 \pm 4$ & 13 & 48 & 61 & 86 & 42 & 128 \\
\hline & - & + & 1 & 240 & 1.6 & $2 \cdot 0$ & 0 & 0 & 0 & 6 & 0 & 0 & 0 & 5 & 12 & 17 \\
\hline & + & + & 4 & $386 \pm 87$ & $11 \cdot 2 \pm 4 \cdot 8$ & $32 \cdot 0 \pm 1 \cdot 4$ & $1 \cdot 1$ & $0 \cdot 8$ & $16 \pm 4$ & $6 \pm 1$ & 6 & 32 & 38 & 11 & 12 & 23 \\
\hline age 45 & - & - & 1 & 344 & 3.0 & $9 \cdot 3$ & Trace & & 4 & 28 & Trace & 8 & 8 & 34 & 56 & 90 \\
\hline & + & - & 5 & $712 \pm 74$ & $13 \cdot 7 \pm 4 \cdot 3$ & $318 \cdot 0 \pm 1 \cdot 9$ & $2 \cdot 4 \pm 0 \cdot 5$ & & $28 \pm 4$ & $36 \pm 4$ & 18 & 56 & 74 & 129 & 72 & 201 \\
\hline & - & + & 1 & 266 & $1 \cdot 3$ & $14 \cdot 8$ & Trace & & 4 & 30 & Trace & 8 & 8 & 39 & 60 & 99 \\
\hline & + & + & 3 & 529 & $3 \cdot 4$ & $11 \cdot 0$ & $2 \cdot 2$ & & 22 & 34 & 14 & 44 & 58 & 65 & 68 & 133 \\
\hline age 43 & - & - & 2 & 206 & $2 \cdot 8$ & $3 \cdot 6$ & 0 & 0.6 & 18 & 6 & 0 & 36 & 36 & 6 & 12 & 18 \\
\hline & + & - & 5 & $534 \pm 91$ & $11 \cdot 8 \pm 3 \cdot 9$ & $0.6 \pm 0.2$ & $8 \cdot 0 \pm 2 \cdot 6$ & $1 \cdot 0$ & $42 \pm 9$ & $5 \pm 0.5$ & 52 & 84 & 136 & 3 & 10 & 13 \\
\hline & - & + & 1 & 201 & $2 \cdot 2$ & $4 \cdot 5$ & 0 & 0 & 19 & 7 & 0 & 38 & 38 & 9 & 14 & 23 \\
\hline & + & + & 2 & 228 & $2 \cdot 4$ & $1 \cdot 8$ & 0 & $1 \cdot 4$ & 56 & 5 & $\mathbf{0}$ & 112 & 112 & 4 & 10 & 14 \\
\hline age 41 & - & - & 1 & 221 & 1.9 & Trace & 0.3 & $0 \cdot 8$ & 14 & 4 & $<1$ & 28 & 28 & Trace & 8 & 8 \\
\hline & + & - & 6 & $744 \pm 197$ & $10 \cdot 6 \pm 4 \cdot 2$ & 2 Trace & $10 \cdot 2 \pm 2 \cdot 0$ & $2 \cdot 1$ & $80 \pm 10$ & $6 \pm 0.5$ & 92 & 160 & 252 & Trace & 12 & 12 \\
\hline & - & + & 1 & 279 & $3 \cdot 0$ & Trace & Trace & $2 \cdot 9$ & 24 & 8 & Trace & 48 & 48 & Trace & 16 & 16 \\
\hline & + & + & 2 & 428 & $12 \cdot 6$ & Trace & $9 \cdot 8$ & $1 \cdot 3$ & 64 & 8 & 42 & 128 & 170 & Trace & 16 & 16 \\
\hline
\end{tabular}

${ }^{1}$ Mean or mean and standard deviation if $n=$ or $>4$.

${ }^{2}$ Assuming pulmonary ventilation to be $2 \times 10^{8} \mathrm{ml}$ per 5 hours. 

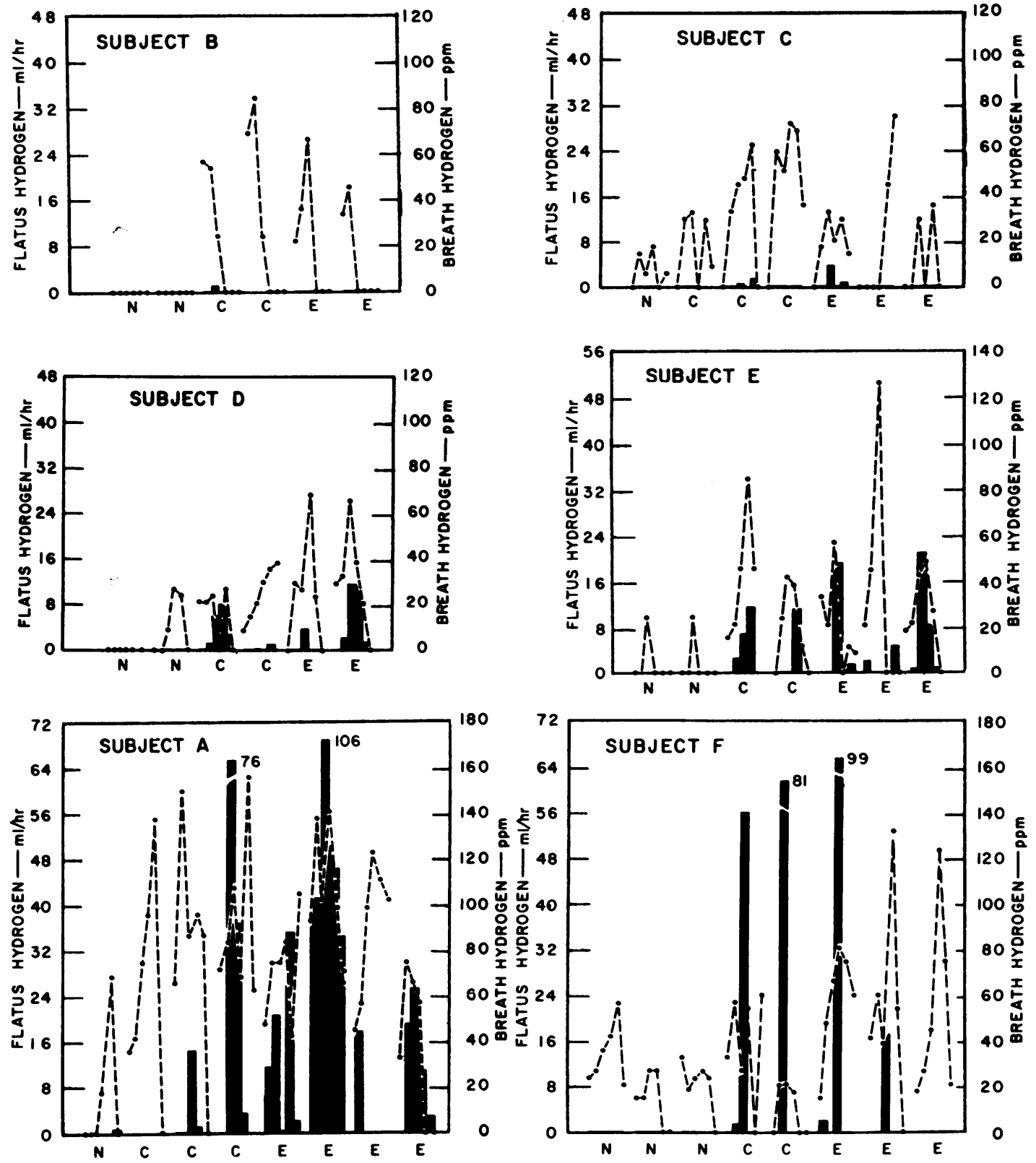

Flatus Hydrogen

$N=$ No Beans;

Breath Hydrogen ---

$C$ and $E=$ Beans

FIG. 1. Hourly (10.30 am to $3.30 \mathrm{pm})$ volume of egested flatus hydrogen and breath hydrogen concentration of men fed a conventional breakfast or canned beans at 8 am. 
breath hydrogen nor methane differed significantly from control values in the other men.

The response to the bean meal was highly variable, both within and among individual subjects (Table I). Two men (B and C) experienced no increase in volume of flatus and, although the remaining four egested an average of at least twice that of the control period, in single tests their volumes were sometimes as low as control collections or seven times as high. However, breath hydrogen was always higher after the bean meal than after the control meal, indicating that all subjects had an increase in intestinal gas formed, whether or not the volume of rectal flatus was increased. Figure 1 displays the time course of the appearance of hydrogen in the breath in separate trials. Peak hydrogen evolution was usually detected between four and six hours after the test meal, in samples collected from 12.30 to $2.30 \mathrm{pm}$.

Subjects B and C, who passed only $1 \mathrm{ml}$ of flatus hydrogen during the five-hour collection periods, exhaled about $50 \mathrm{ml}$ of hydrogen in the breath, assuming normal pulmonary ventilation. Volumes of flatus of subjects $D$ and $E$ about doubled with bean feeding. Their slight elevation of flatus hydrogen (to 13 and $18 \mathrm{ml}$ ) was also accompanied by approximately $50 \mathrm{ml}$ of breath hydrogen.

Subjects F and A not only had increased breath hydrogen following bean meals but they usually passed large volumes of gas from the rectum as well. Subject F's maximum measured flatus volume of $714 \mathrm{ml}$ included $101 \mathrm{ml}$ of hydrogen; during the same period, he exhaled about $120 \mathrm{ml}$ of hydrogen. Extreme variability is seen in his data. One recorded value was not appreciably greater than his control output, $272 \mathrm{ml}$; accompanying this, however, was an average breath hydrogen concentration of 51 $\mathrm{ppm}$, indicating about $100 \mathrm{ml}$ of hydrogen removed from the lungs. Subject A also passed variable, large amounts of flatus, and none of his test volumes overlapped control values. With beans, his minimum volume was $337 \mathrm{ml}$ of rectal flatus and his maximum volume, $1,630 \mathrm{ml}$, was about double the next largest one, $847 \mathrm{ml}$. Subject A's record production was $269 \mathrm{ml}$ of flatus hydrogen, when his respiratory exchange accounted for another $212 \mathrm{ml}$ of hydrogen.

Breath methane was not influenced by the bean meal, even in subjects $D$ and $E$, in whom egestion of this gas from the rectum increased about fourfold. In general, then, breath hydrogen rose and and breath methane remained constant during six hours after the bean meal in all subjects, irrespective of changes in volume or composition of flatus.

Changes in the composition of rectal gas were not uniform, though certain trends were apparent. The subjects who did not respond to beans with excess flatus (B and C) had very little change in either hydrogen or methane concentrations in rectal gas. Subjects $\mathrm{D}$ and $\mathrm{E}$ were methane producers in the control situation (about $10 \%$ of flatus as methane) and experienced further increase in methane concentration and gas volume, but little elevation of flatus hydrogen. On the other hand, subjects $F$ and A responded to beans with an increased volume of flatus and hydrogen concentration, but little change in methane concentration. Carbon dioxide concentration rose after the bean meal in all subjects, but the increase was more marked in those who produced a greater volume of gas than it was in subjects $B$ and $C$.

The addition of silicone to the beans neither increased the amount of flatus egested from the rectum nor altered the concentration of hydrogen in the breath (Table I). In fact, there was a trend, among the four subjects who passed increased volumes of gas after eating beans without silicone, toward decreased volumes of flatus. However, the range of values is so great within the subjects that an effect cannot be clearly demonstrated from so few observations. As in his control series, subject D again had a very reduced production of methane in the presence of silicone. There is a suggestion in the data of subject $F$ that the volume of flatus hydrogen was also reduced with silicone.

\section{DISCUSSION}

Previously, it was shown that ileal dejecta yield hydrogen, but not methane, after incubation, and colostomy residues produce both gases (Calloway, Colasito, and Mathews, 1966). Using a direct gas perfusion technique, Levitt and Ingelfinger have more recently reported that hydrogen is found in the lower ileum and caecum; methane appears, with hydrogen, further on in the transverse colon (Levitt and Ingelfinger, 1968). The divergent behaviour of hydrogen and methane in our study confirms the earlier impression that their site of origin differs. The large bowel has less diffusion capacity than does the small intestine, owing to its lower ratio of surface (and blood flow) to volume. Thus, any alteration in the production of gas low in the bowel should be more evident in rectal than in breath gases, as is the case with methane. The marked elevation in breath hydrogen, even in the absence of increased volume of flatus or content of hydrogen, is consistent with production higher in the gut and/or a more rapid removal rate. Also favouring diffusion of hydrogen over methane is its lower molecular weight.

It is interesting that the amounts of rectal gas produced in the control situation were quite similar 
in all subjects and did not predict the response to beans. A possible indicator of predisposition to excessive production of gas among the men studied was the presence of a high concentration of either methane or hydrogen in control breath samples. The two subjects who did not respond to the bean meal with increased volumes of flatus had low concentrations of both gases in control breath samples. Patterns of hydrogen and methane in breath and flatus may well reflect the abundance and site of certain gas-producing organisms in the gut. Recognizing that faecal samples are of doubtful value in discriminating among hydrogen-producing subjects, we did, nevertheless, carry out a small study of possible differences relative to methane. Faecal samples were collected from the rectal catheters during the last three days of study and bacteria were enumerated and partially classified by conventional methods. The subjects who produced large volumes of methane also had high counts of anaerobic organisms. Clostridia were approximately twice as abundant and coliform types 30 to $60 \%$ higher in these men than in subjects with low methane values.

The only effect of silicone observed in the control situation was a specific depression of methane production in one subject. In subjects who produced large volumes of flatus in response to the bean meal, the simultaneous presence of silicone tended to lower the volume of flatus and, in one case each, methane and hydrogen specifically. These data suggest an effect of silicone on growth or metabolic activity of certain intestinal microorganisms.

Differences in flora should be most evident when the milieu provides ample substrate for fermentation. Thus, differences in digestion and absorption, including the rate of passage of chyme, could induce variability in gas production by making available more or less substrate at lower levels of the gut. No such differences were known to exist among subjects of this study, either historically or experientially, with one possible exception. Subject A's very large egestion of flatus coincided with a distressful discussion between the subject and a member of the medical staff concerning health matters unrelated to this study; psychogenically altered motility could have been a feature of this exceptional response. Modification of intestinal blood flow might also contribute to variability by changing the rate at which gas was removed.
SUMMARY

The volume and composition of flatus were measured on several occasions in six healthy men following a conventional breakfast and a bean meal, with and without added silicone. Breath samples taken at hourly intervals throughout the period of flatus collection were analysed for two gases of intestinal origin, hydrogen and methane. Response to beans varied markedly from day to day, both among and within subjects. Two subjects showed no increase in flatus after consuming beans, but all subjects, including those who had no increased flatus, reacted to bean feeding with an elevation of the breath hydrogen concentration. Methane concentration in the breath was not affected by bean feeding, although the volume of methane in flatus increased in the two subjects whose control samples also contained large amounts of this gas. In one of these men, methane content of both flatus and breath was sharply reduced with silicone. Flatus, but not breath hydrogen concentration, was lowered with silicone in another man, one who usually experienced bean-induced flatulence. These patterns may reflect differences in type, site, and abundance of intestinal microorganisms.

The authors wish to thank Drs Leo E. Hollister and Jack Shelton of the Veteran's Administration Hospital, Palo Alto, for their cooperation in arranging for test subjects and for use of their facilities, and Mr Richard Mathews and $\mathrm{Dr}$ Herbert Stone for their generous participation in the project.

\section{REFERENCES}

Calloway, D. H. (1966). Respiratory hydrogen and methane as affected by consumption of gas-forming foods. Gastroenterology, 51, 383-389.

_- Colasito, D. J., and Mathews, R. D. (1966). Gases produced by human intestinal microflora. Nature (Lond.), 212, 1238-1239.

Kirk, E. (1949). The quantity and composition of human colonic flatus. Gastroenterology, 12, 782-794.

Levitt, M. D., and Ingelfinger, F. J. (1968). Hydrogen and methane production in man. Ann. N.Y. Acad. Sci., 150, 75-81.

McIver, M. A., Redfield, A. C., and Benedict, E. B. (1926). Gaseous exchange between the blood and the lumen of the stomach and intestines. Amer. J. Physiol., 76, 92-111.

Pogrund, R. S., and Steggerda, F. R. (1948). Influence of gaseous transfer between the colon and blood stream on percentage gas compositions on intestinal flatus in man. Ibid., 153, 475-482.

Rider, J. A., and Moeller, H. C. (1960). Use of silicone in the treatment of intestinal gas and bloating. J. Amer. med. Ass., 174, 20522054. 